\title{
Primer caso de meningitis por Streptococcus suis en el noroeste de Argentina
}

\author{
Juan M. Núñez, Mariana Marcotullio, Andrea Rojas, Luis Acuña, \\ Mariel Cáceres y Silvana Mochi
}

\footnotetext{
Hospital Angel C. Padilla, San Miguel de Tucumán, Argentina. Residencia de Infectología (JMN, MM) Servicio de Medicina Interna (AR) Laboratorio de Bacteriología (LA, MC, SM)

Recibido: 28 de noviembre de 2012 Aceptado: 20 de junio de 2013

Correspondencia a: Juan M. Nuñez juanmanuelnunez@me.com
}

\section{First case of meningitis by Streptococcus suis in the norwest area of Argentina}

Streptococcus suis causes meningitis, bacteremia, endocarditis, endophthalmitis, artrithis and toxic shock in both pigs and human beings. The incidence of this pathogen is increasing worldwide. A case of 54 years old men from a rural zone of Tucumán, Argentina with two days of headache, vomit and photophobia was admitted septic, with purulent meningitis. Streptococcus suis was growth from the blood and cerebrospinal fluid culture. The patient was treated with ceftriaxona and had a good evolution without sequels. This is the first case of S. suis described in the northwest of Argentina and the third of Latin America, and it is emphasized that the occupational contact with pigs is an important background for the initial suspect of this pathogen.

Key words: Meningitis, Streptococcus suis, Argentina

Palabras clave: Meningitis, Streptococcus suis, Argentina.

(Artículos relacionados en páginas 539 y 557)

\section{Introducción}

L a meningitis por Streptococcus suis es una zoonosis de creciente notificación en el mundo ${ }^{1,2}$. Es una cocácea grampositiva que coloniza el tracto respiratorio, digestivo y genital del ganado porcino y responsable de frecuentes patologías en cerdos de corta edad $^{3,4}$. Puede transmitirse al ser humano por contacto directo o por la ingesta de carne mal cocida, por lo que las personas con exposición laboral tienen mayor riesgo ${ }^{5}$. En el hombre, S. suis puede causar meningitis, bacteriemia, endocarditis, endoftalmitis, artritis y shock tóxico, tanto en personas inmunocompetentes como inmunocomprometidas ${ }^{4,6}$. A pesar de que su mortalidad es baja, las secuelas neurológicas, tales como sordera y ataxia, son frecuentes ocurriendo en alrededor de 50 a $65 \%$ de los pacientes ${ }^{4,6,7}$.

Desde la primera descripción en humanos, en Dinamarca en $1968^{8}$, se han reportado cada vez más casos de infecciones por esta bacteria, especialmente en China, Tailandia y Países Bajos. En el año 2005 se comunicó en Sichuan (China) un brote de 204 casos documentados con 38 muertes $^{8 a}$. Hasta ahora se han publicado sólo dos casos de meningitis por $S$. suis en Latinoamérica, ambos provenientes de Argentina: el primero en 2005, en la Provincia de Buenos Aires y el segundo en 2008, oriundo de Santa Fe. Aquí presentamos el tercer caso documentado de Argentina y Latinoamérica.

\section{Caso clínico}

Paciente de sexo masculino, con 54 años de edad, sin antecedentes personales ni familiares relevantes, procedente de una zona rural del interior de la provincia de Tucumán, Argentina.

Acudió al Servicio de Urgencia de nuestro hospital, con un cuadro de cefalea, vómitos y fotofobia leve de dos días de evolución. Al examen físico estaba febril con $38^{\circ} \mathrm{C}$, taquicárdico, lúcido, vigil, orientado, con rigidez de nuca y lesiones vesiculosas en el labio superior, de apariencia herpética.

Se realizaron exámenes generales: hemograma con 26.800 leucocitos, $93 \%$ de neutrófilos y $3 \%$ de neutrófilos baciliformes, hematocrito $39 \%$, hemoglobina $12,9 \mathrm{~g} / \mathrm{dl}$, VHS $112 \mathrm{~mm} 1^{\circ}$ hora, glicemia $140 \mathrm{mg} / \mathrm{dl}$, función renal y hepática normales. En la tomografía axial computada (TAC) de cerebro no se evidenciaron lesiones. Se realizó una punción lumbar que dio salida a un líquido cefalorraquídeo (LCR) de aspecto turbio, con proteínas $201 \mathrm{mg} /$ dl, glucorraquia $0 \mathrm{mg} / \mathrm{dl}$, LDH $204 \mathrm{mg} / \mathrm{dl}, 294$ céls $/ \mathrm{mm}^{3}$ con predominio de neutrófilos. En la tinción de Gram se observaron diplococos grampositivos lanceolados que hizo sospechar Streptococcus pneumoniae. La coloración de Ziehl Neelsen y tinta china fueron negativas.

Con el diagnóstico de meningitis bacteriana aguda se inició tratamiento empírico con ceftriaxona iv $2 \mathrm{gr}$, dos veces al día y dexametasona iv. 
Tanto en el cultivo de LCR como en los dos hemocultivos, realizados en el sistema Bact/ALERT ${ }^{\circledR} 3 \mathrm{D}$, se aislaron colonias grises, lisas, de bordes enteros, $\beta$-hemolíticas en agar sangre, catalasa negativas. La aglutinación frente al antisuero de Streptococcus pneumoniae fue negativa. La serotificación para antígenos de Lancefield con Slidez Strepto $\mathrm{Kit}^{\circledR}$ (Biomerieux) produjo aglutinación con el antisuero del grupo D. La identificación del microorganismo mediante pruebas fenotípicas se realizó con optoquina, catalasa, hemólisis en agar sangre, bacitracina, bilis esculina, pyr, lap y telurito (Tabla 1).

La especie se confirmó mediante el sistema Vitek ${ }^{\circledR} 2$ Compact (Biomerieux), que identificó el microorganismo como Streptococcus suis biotipo 1 (50\%), biotipo 2 (50\%). Se realizó el antibiograma por método de difusión en agar sangre, resultando sensible a levofloxacina, penicilina, eritromicina, clindamicina, rifampicina, cotrimoxazol y vancomicina y resistente a oxacilina, con resultados coincidentes con los del sistema automatizado.

El paciente evolucionó favorablemente a las $24 \mathrm{~h}$ de iniciado el tratamiento antibacteriano. Se mantuvo afebril y sin signos meníngeos ni otras alteraciones neurológicas hasta el alta, luego de 14 días posteriores al ingreso.

Con la información del cultivo, se indagó en profundidad sobre los antecedentes epidemiológicos del paciente, constatándose que se dedicaba a la cría de ganado porcino, bovino y equino en su domicilio.

Luego de realizar la denuncia epidemiológica correspondiente, veterinarios del Departamento de Zoonosis de la Provincia realizaron la inspección del domicilio del paciente. Se constató una vivienda precaria, con ocho cerdos en mal estado higiénico y nutricional a los cuales se les tomaron muestras para cultivo por hisopados nasal, rectal y vaginal. Los resultados de dichas muestras fueron negativos para $S$. suis.

Se realizó el control clínico y neurológico a los seis meses del alta, encontrándose sin evidencia de complicaciones ni secuelas, con audiometría normal, continuando actualmente en seguimiento ambulatorio.

\section{Discusión}

Similar al caso comunicado en la provincia de Santa Fe, Argentina, en 2008 por Nagel y cols., se presenta un caso de meningitis y bacteriemia por $S$. suis $^{10}$. El caso descrito corresponde a un paciente inmunocompetente, a diferencia de lo publicado en la literatura científica, donde se ha asociado a algún tipo de inmunocompromiso predisponente (esplenectomía) ${ }^{11,12}$. Al igual que lo publicado en diversas series, el paciente en cuestión también presentaba antecedentes de exposición laboral a cerdos, aunque no se pudo constatar la puerta de entrada cutánea, como en uno de los casos presentado por Asensi JM y cols ${ }^{9}$.

Streptococcus suis tiene una baja mortalidad, alrededor
Tabla 1. Características fenotípicas de Streptococcus suis de cultivos de sangre y LCR

\begin{tabular}{|ll|}
\hline Pruebas fenotípicas & Resultados \\
\hline Hemólisis en sangre humana & Tipo $\beta$ \\
\hline Catalasa & Negativa \\
\hline Optoquina & Resistente \\
\hline Oxacilina & Resistente \\
\hline Bacitracina & Resistente \\
\hline Cotrimoxazol & Resistente \\
\hline Bilis-esculina & Negativa \\
\hline Pirrolidonil-aminopeptidasa & Negativa \\
\hline Leucin-aminopeptidasa & Positiva \\
\hline Telurito & Negativa \\
\hline Aglutinación en latex & Grupo D positiva (Slidex Strepto Plus) grupo B negativa (Lancefield) \\
\hline
\end{tabular}

de $7 \%$ en los humanos infectados, comparado con el resto de las meningitis bacterianas del adulto que superan en promedio el $21 \%{ }^{13,14}$. En más de $50 \%$ de los casos se pueden presentar complicaciones como la hipoacusia bilateral permanente, atribuida a una laberintitis supurativa por acción directa de exotoxinas a nivel coclear ${ }^{7}$, que podría ser prevenida con el uso de corticosteroides ${ }^{10}$. Otras secuelas neurológicas son excepcionales habiéndose descrito casos de paresias y parálisis de pares craneales ${ }^{6}$. En el caso que aquí presentamos no se constató secuela alguna.

Tal como lo mencionan Nagel y cols. ${ }^{10}$, es fundamental investigar acerca de la actividad laboral de los pacientes para sospechar de este agente etiológico, debido a su importancia epidemiológica. Esta infección debe ser considerada como una zoonosis y es necesario que la población en riesgo extreme las medidas higiénicas y preventivas ante heridas ocurridas durante la manipulación de carne de ganado porcino ${ }^{10}$.

Si bien las malas condiciones higiénicas y nutricionales de los cerdos del paciente podrían haber predispuesto a la transmisión del microorganismo, no pudo detectarse la presencia de $S$. suis en los cultivos tomados en ganado porcino.

La confirmación del microorganismo en este caso fue realizada por el sistema Vitek ${ }^{\circledR} 2$ Compact, utilizado también por otros autores ${ }^{6,14,17}$. Al igual que en numerosas publicaciones ${ }^{10,11,15,16}$, no se realizó documentación por biología molecular, hecho que le hubiera dado más riqueza diagnóstica.

Se decidió completar el tratamiento con ceftriaxona, en lugar de penicilina $\mathrm{G}$, debido a la favorable respuesta inicial, y a la numerosa evidencia de casos clínicos publicados con cefalosporinas de tercera generación ${ }^{10,11,16,17}$.

Si bien las comunicaciones de casos en humanos de infecciones por S. suis han ido en aumento en el mundo ${ }^{1}$, en Latinoamérica sólo se han publicado dos pertenecientes a la zona centro-este de Argentina ${ }^{10,11}$. 
El aislamiento de $S$. suis presentado tiene como propósito alertar a la comunidad hospitalaria acerca de este microorganismo y estimular la sospecha y búsqueda del mismo en la región.

Agradecimientos: Agradecemos en especial a Mónica Herbst, Berta Bustamante, al Departamento de Emergencias, a los Servicios de Bacteriología, Infectología, Infectología y Clínica Médica del Hospital Ángel C. Padilla, por su dedicación y trabajo en equipo.

\section{Resumen}

La infección por Streptococcus suis puede causar meningitis, bacteriemia, endocarditis, endoftalmitis, artritis y shock tóxico, tanto en el ser humano como en cerdos. La incidencia de esta zoonosis está aumentando en el mundo. Se presenta el caso de un varón de 54 años de edad, trabajador rural proveniente de la provincia de Tucumán, Argentina, que consultó por cefalea, vómitos y fotofobia de dos días de evolución, constatándose una sepsis de foco meníngeo. Tanto en el cultivo de líquido cefalorraquídeo como en el hemocultivo se aisló $S$. suis. Se trató con ceftriaxona con buena evolución y sin secuelas. Es el primer caso de $S$. suis en el noroeste argentino y el tercero en Latinoamérica. Se resalta la importancia del antecedente de exposición laboral a cerdos para la sospecha inicial de este microorganismo.

\section{Referencias bibliográficas}

1.- Lun Z R, Wang Q P, Guang Chen X G, Li A X, Zhu X Q. Streptococcus suis: an emerging zoonotic pathogen. Lancet Infect Dis 2007; 7: 201-9.

2.- Wertheim HF, Nghia HD, Taylor W, Schultsz C. Streptococcus suis: an emerging human pathogen. Clin Infect Dis 2009; 48: $617-25$.

3.- $\quad$ Staats J J, Feder I, Okwumabua O, Chengappa M M. Streptococcus suis: past and present. Vet Res Commun 1997; 21: 381-407.

4.- $\quad$ Segura M. Streptococcus suis: an emerging human threat. J Infect Dis 2009; 199: 4-6.

5.- Luengo-Álvarez J, Martín-Ruiz C, Sánchez Muñoz-Torrero J F, IñiguezOvando R. Meningitis por Streptococcus suis: a propósito de un caso. Enferm Infecc Microbiol Clin 2006; 24: 352-5.

6.- $\quad$ Huh H J, Park K J, Jang J H, Lee M, Lee J H, Ahn Y H. Streptococcus suis meningitis with bilateral sensorineural hearing loss. Korean J Lab Med 2011; 31: 205-11.

7.- $\quad$ Tan J H, Yeh B I, Seet C S . Deafness due to haemorrhagic labyrinthitis and a review of relapses in Streptococcus suis meningitis. Singapore Med J 2010; 51: e30-3.

8.- Perch B, Kristjansen P, Skadhauge K. Group R Streptococci pathogenic for man: two cases of meningitis and one fatal case of sepsis. Acta Pathol Microbiol Scand 1968; 74: 69-76.

8a.- World Health Organization Regional Office for the Western Pacific. Outbreak associated with Streptococcus suis in pigs in China: update 2005. http://www.who.int/zoonoses/outbreaks/ zoonosesoutbreaksuis1/en/index.html

9.- Asensi J M, Asensi V, Arias M, Moreno A, Navarro R. Meningitis por Streptococcus suis. A propósito de dos casos y revisión de la bibliografía. Enferm Infecc Microbiol Clin 2001; 19: 186-8.

10.- Nagel A, Manias A, Busquets S, Sniadowsky S, Andazardi J, Mendez Ede L. Meningitis por Streptococcus suis en un paciente inmunocompetente. Rev Argent Microbiol 2008; 40: 158-60.

11.- Lopreto C, Lopardo H A, Bardi M C, Gottschalk M. Meningitis primaria por Streptococcus suis: primer caso en humanos descrito en América Latina. Enferm Infecc Microbiol Clin 2005; 23: 110

12.- Gallagher F. Streptococcus suis infection and splenectomy. Lancet 2001; 357: 1129-30.

13.- Tang J, Wang C, Feng Y, Yang W, Song H, Chen Z, et al. Streptococcal toxic shock syndrome caused by Streptococcus suis serotype 2. PLoS Med 2006; 3: e 151.

14.- van de Beek D, de Gans J, Spanjaard L, Weisfelt M, Reitsma J B, Vermeulen M. Clinical features and prognostic factors in adults with bacterial meningitis. N Engl J Med 2004; 351: 1849 -59.

15.- Kim H, Lee S H, Moon H W, Kim J Y, Lee S H, Hur M, et al. Streptococcus suis causes septic arthritis and bacteremia: phenotypic characterization and molecular confirmation. Korean J Lab Med 2011; 31: 115-7.

16.- Fernández-Ferro J, López-González F J, Pardo F, Pías-Peleteiro J M. Meningitis aguda por Streptococcus suis en una criadora de cerdos. Enferm Infecc Microbiol Clin 2011; 29: 396-402.

17.- Mai N T, Hoa N T, Nga T V, Linh le D, Chau T T, Sinh D X, et al. Streptococcus suis meningitis in adults in Vietnam. Clin Infect Dis 2008; 46: 659-67.

19.- Fittipaldi N, Collis T, Prothero B, Gottschalk M. Streptococcus suis meningitis, Hawaii. Emerg Infect Dis 2009; 15: 2067-9. 